\title{
Factors Influencing Community Event-based Surveillance: Lessons Learned from Pilot Implementation in Vietnam
}

Alexey Clara, Anh T. P. Dao, Trang T. Do, Phu D. Tran, Quang D. Tran, Nghia D. Ngu, Tu H. Ngo, Hung C. Phan, Thuy T. P. Nguyen, Christina Bernadotte-Schmidt, Huyen T. Nguyen, Karen Ann Alroy, S. Arunmozhi Balajee, and Anthony W. Mounts

Community event-based surveillance aims to enhance the early detection of emerging public health threats and thus build health security. The Ministry of Health of Vietnam launched a community event-based surveillance pilot program in 6 provinces to improve the early warning functions of the existing surveillance system. An evaluation of the pilot program took place in 2017 and 2018. Data from this evaluation were analyzed to determine which factors were associated with increased detection and reporting. Results show that a number of small, local events were detected and reported through community event-based surveillance, supporting the notion that it would also facilitate the rapid detection and reporting of potentially larger events or outbreaks. The study showed the value of supportive supervision and monitoring to sustain community health worker reporting and the importance of conducting evaluations for community event-based surveillance programs to identify barriers to effective implementation.

Keywords: Global health security, Community event-based surveillance, Early detection

$\mathrm{C}$ OMMUNITY EVENT-BASED SURVEILlanCe involves community-level participation in detecting and reporting signals that may represent emerging events of public concern. ${ }^{1-7}$ Signals may be information or reports of individual cases or deaths, clusters of cases with similar symptoms, exposure of human beings to hazards, or occurrences of natural or man-made disasters. ${ }^{8,9}$ The eventbased surveillance approach differs from indicator-based surveillance activities: It relies on the recognition of disease patterns, rather than the recognition and reporting of

Alexey Clara, MD, MPH, is an Epidemiologist, Global Health Sciences; Karen Ann Alroy, DVM, MPH, is an Epidemiologist Global Health Sciences; and S. Arunmozhi Balajee, PhD, is Associate Director for Global Health Sciences, Office of the Director; all in the Division of Viral Diseases; National Center for Immunization and Respiratory Diseases; Centers for Disease Control and Prevention (CDC), Atlanta, Georgia. Anh T. P. Dao, MPH, is GHSA Surveillance Officer, Surveillance \& Response Team, and Trang T. Do, $\mathrm{PhD}$, is Surveillance \& Response Team Lead; both in the Division of Global Health Protection, US CDC, U.S. Embassy Annex, Hanoi, Vietnam. Phu D. Tran, PhD, is General Director, and Quang D. Tran, PhD, is EBS focal point, Communicable Disease Control Division; both are in the General Department of Preventive Medicine, Vietnam Ministry of Health, Hanoi, Vietnam. Nghia D. Ngu, PhD, is Acting Head, and Tu H. Ngo, MPM, is a Researcher; both in the Department of Communicable Disease Prevention and Control, National Institute of Hygiene and Epidemiology, Hanoi, Vietnam. Hung C. Phan, MD, and Thuy T. P. Nguyen, MD, are Researchers, Department of Communicable Diseases Prevention and Control Pasteur Institute in Ho Chi Minh City, Vietnam. Christina Bernadotte-Schmidt, MPH, is a Monitoring, Evaluation and Learning Officer, Results Management, Measurement, and Learning, PATH, Seattle, Washington. Huyen T. Nguyen, MSPH, BPharm, is Senior M\&E Officer, Global Health Security Partnership, PATH, Hanoi, Vietnam. Anthony W. Mounts, MD, is Country Director, Division of Global Health Protection, US CDC, Hanoi, Vietnam. 
specific diseases using case definitions. ${ }^{8,9}$ Signals may be reported from many different sources in event-based surveillance, whereas indicator-based surveillance systems typically derive information from routinely and regularly reported numbers of disease cases from healthcare facilities.

Signals are deliberately designed to be broad, as the goal is to have a detection system of high sensitivity; signals can be adjusted to optimize sensitivity and specificity in specific settings. ${ }^{8,9}$ Community-level signals are designed to be simple so that village health workers and community members may participate in community event-based surveillance. Upon notification of signals by the community to the public health authorities, the signals must be verified and triaged by trained public health workers to determine if they truly represent a public health threat before any response is initiated. In Vietnam, once a signal has been verified, it is called an "event"; an event then requires a response from the public health authorities. ${ }^{8,9}$ Triage and verification of incoming signals are crucial steps to reduce the background noise from non-events and subsequent over-burdening of the response system; it requires a dialogue between commune health stations (CHSs) and district levels. ${ }^{8-10}$ In addition, the district shares information and updates on reported events with the respective CHS, which in turn shares this information with community health workers in routine meetings.

The Ministry of Health of Vietnam has recognized the need to improve the sensitivity of outbreak detection systems and accelerate progress toward a national capacity to prevent, detect, and respond earlier to events and outbreaks, so as to meet the country's obligations under the International Health Regulations (IHR 2005) and strengthen capacities in the Global Health Security Agenda (GHSA) framework. ${ }^{11}$ Accordingly, the ministry of health developed an event-based surveillance program to complement the existing routine indicator-based surveillance system. ${ }^{10}$ Signals were developed by a technical working group, which also developed guidelines, training materials, and advocacy tools. The implementation of community event-based surveillance was launched as a Phase 1 pilot program in 2016 in 43 districts in 4 provinces in Vietnam: Quang Ninh and Nam Dinh in the north region, and An Giang and Ba Ria Vung Tau in the south region. ${ }^{10}$ Building on the experience of the Phase 1 pilot in the 4 provinces, the ministry of health expanded the pilot program in August 2017 to include 2 additional provinces: 1 from the central highlands region (Dak Nong), and the other from the south central coast region (Binh Thuan) (Phase 2). The process of implementation and evaluation are described in detail in a previously published article. ${ }^{10}$

Phase 1 of the pilot program was evaluated in 2017, while Phase 2 was evaluated in 2018, each about 6 months after implementation. The current article presents a detailed analysis of data collected during the evaluation and describes the factors that were associated with increased signal reporting and improved event-to-signal ratio at the community level. The article also describes lessons learned from the pilot implementation; the ministry of health is currently using these lessons in the national scale-up of the community event-based surveillance.

\section{Methods}

\section{Surveillance Structure}

Vietnam has 4 administrative health regions, each with a regional public health institute $(\mathrm{RI})$ that is responsible for the overall supervision of outbreak surveillance and response. Within each region, provincial preventive medicine centers (PPMCs) lead public health surveillance and response activities within their respective provinces, involving the regional institute for larger events. The provincial preventive medicine centers are supported by 2 lower administrative levels, the district health centers (DHCs) and commune health stations. Commune health stations are generally staffed by a physician, a nurse, and a variable number of village health workers who work largely on a voluntary basis. All outbreaks are ultimately reported upward through each administrative level; however, the urgency with which reporting occurs and the level at which response occurs depends on several characteristics, such as the size, severity, and progression of the event. The district health center and commune health station conduct regular meetings with village health workers to ensure a feedback loop is completed. The provinces and districts for this pilot were selected by the ministry of health in collaboration with the regional institutes based on criteria that included provinces with districts along international borders, mobile populations, accessibility and connectivity, and the presence of willing leadership at provincial preventive medicine centers and district health centers.

\section{Data Collection}

Population data were extracted from the 2009 population census and the General Statistics Office of Vietnam. ${ }^{12}$ Data collection tools for the evaluation included: (1) a form for data extraction from district-level logbooks and monthly community event-based surveillance summary reports that provided the number, type of signals, and events reported, as well as the time of detection and reporting by district; (2) a simple table sent electronically to pilot provinces to collect the type and number of training sessions and the number of people trained; and (3) an online survey tool with questions aimed at understanding the acceptability and sustainability of the pilot program and to obtain feedback on the training sessions. The online survey also included questions on demographics (eg, age, sex, education level of implementers), barriers faced in implementing community event-based surveillance, and types 
of key informants detecting and reporting signals. The survey was sent to all village health workers, commune health stations, district health centers, and provincial preventive medicine centers participating in the pilot project. Most online survey questions were based on a Likert scale model. The online survey was used only in Phase 1 provinces.

\section{Data Analyses}

The incidence rate for signal reporting was calculated as the number of signals detected from each province and district per 100,000 population for the number of days engaged in signal reporting. In addition, the ratio of events to signals in all provinces (Phase 1 and Phase 2) over time was calculated as events detected per month divided by signals detected per month. Event-to-signal ratio was compared between Phase 1 and Phase 2 provinces for the first 5 months of implementation in each group to understand the effect of introducing a modified signal list during Phase 2 implementation. The median number of signals reported per commune was also calculated to assess the burden of the program on commune health stations.

Data on factors that may have influenced implementation in individual districts were only available from Phase 1 provinces, as these data were collected primarily through the online survey. Individual responses from the survey were aggregated at the district level as a percentage for each variable. The unit of analysis was the district for both univariate and multivariate analyses. Univariate analyses used district demographic data (total population, population density, district type [urban or rural], village health worker density per 1,000 population) and data from the survey tool (type of training, information sources in the community). For the regression analysis, variables included total population, population density, district type (urban or rural), village health worker density per 1,000 population, and the proportion of communities within districts that had community members and teachers as active reporters. Pearson correlation tests were conducted between the continuous explanatory and outcome variables to identify possible associations. For categorical variables, $t$-tests were conducted to compare the mean incidence. For both, the significance level was determined as $p<0.05$.

\section{REsUlts}

The pilot implementation of community event-based surveillance was done in 2 phases (Figure 1). Signals that were used in Phase 1 were revised after field evaluation ${ }^{10}$ and included in Phase 2 implementation (Table 1). From September 2016 to December 2017, 4,854 signals and 370 events were reported by all provinces participating in both Phase 1 and Phase 2 of the pilot program. Data on the type of event were available for 253 events and included a variety of endemic diseases, vaccine-preventable diseases, and zoonoses (Table 2). The signal incidence rate had a slight downward

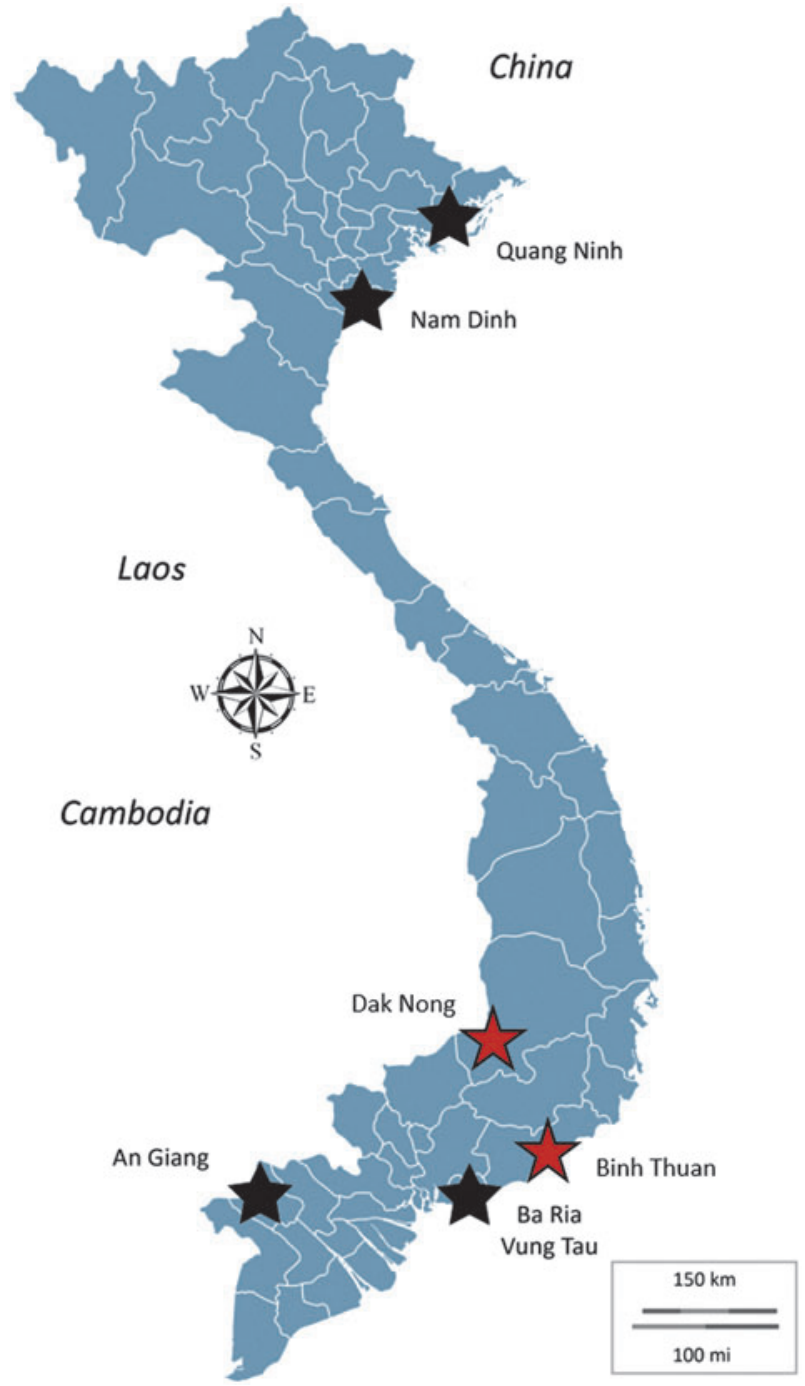

Figure 1. Provinces that implemented the event-based surveillance pilot program (Phase 1, black starts, and Phase 2, red stars), Vietnam, September 2016-December 2017.

linear trend over the 16-month period of Phase 1; however, the ratio of events to signals slightly increased during that period, including marked increases at several specific points during that timeframe (Figure 2). These points roughly correspond to 3 specific interactions with implementers: in February 2017, a team from the ministry of health and the US Centers for Disease Control and Prevention (CDC) conducted supportive monitoring of all 4 provinces that included site visits, logbook review, and interviews with select districts and communes. In June 2017, an evaluation of the community event-based surveillance was conducted by a ministry of health/CDC team, which included many discussions with provincial preventive medicine center leaders on community event-based surveillance and ways to improve event-to-signal ratio. Finally, in October 2017, the Phase 1 provinces were asked to begin using the revised signal list for community event-based surveillance implementation in their jurisdiction and some refresher training was done. 
Table 1. List of Signals from Phase 1 and Phase 2 Implementation

\begin{tabular}{|c|c|}
\hline Phase 1 & Phase 2 \\
\hline \multicolumn{2}{|l|}{ Signals for the community } \\
\hline \multirow{2}{*}{$\begin{array}{l}\text { 1. A single case of any of the following: } \\
\text { - Acute watery diarrhea with severe dehydration or death } \\
\text { in any person } 5 \text { years of age or older } \\
\text { - Acute respiratory infection with fever, or death in } \\
\text { someone who has been traveling abroad in the last } 2 \\
\text { weeks } \\
\text { - A child less than } 15 \text { years of age with a sudden onset of } \\
\text { - Acute flaccid paralysis } \\
\text { - tion } \\
\text { - Sudden death of unknown cause } \\
\text { - Fever and cough, leading to death, and had been in } \\
\text { contact with poultry }\end{array}$} & $\begin{array}{l}\text { 1. One child (less than } 15 \text { years old): } \\
\text { - with sudden weakness of limbs } \\
\text { - fever, rash, respiratory infection, and possibly red eyes }\end{array}$ \\
\hline & $\begin{array}{l}\text { 2. A single case severe enough to require admission to hospital } \\
\text { or causing death of any of the following: }{ }^{c} \\
\text { - Three or more rice watery stools in } 24 \text { hours, any person } \\
5 \text { years of age or older with dehydration } \\
\text { - A new respiratory infection with fever in someone who } \\
\text { has been traveling abroad in the last } 14 \text { days } \\
\text { - A new respiratory infection with fever after contact with } \\
\text { live poultry } \\
\text { - Illness within } 14 \text { days following vaccination } \\
\text { - Illness never seen before or rare symptoms in the } \\
\text { community }\end{array}$ \\
\hline $\begin{array}{l}\text { 2. Two or more cases occurring in the same community, school, } \\
\text { or workplace in the same } 1 \text {-week period of any of the } \\
\text { following: } \\
\text { - High fever with febrile rash } \\
\text { - Children under } 5 \text { years of age with blisters on hand, } \\
\text { foot, and mouth } \\
\text { - Unexpected or unexplained illness from the same type of } \\
\text { acute illness } \\
\text { - Diarrhea associated with a specific setting such as a } \\
\text { wedding, party, social event, school, or individual } \\
\text { restaurant }\end{array}$ & $\begin{array}{l}\text { 3. Two or more hospitalized cases and/or death with similar } \\
\text { type of symptoms occurring in the same community, school, } \\
\text { workplace in the same } 7 \text {-day period }{ }^{\mathrm{d}}\end{array}$ \\
\hline $\begin{array}{l}\text { 4. A dog that is suspected to be rabid or a dog that has bitten } 2 \\
\text { or more people in the last week } \\
\text { 5. Person bitten by a dog that is suspected to be rabid }\end{array}$ & $\begin{array}{l}\text { 4. A dog that is suspected to be rabid or: } \\
\text { - A sick dog that has bitten someone } \\
\text { - Any dog that has bitten } 2 \text { or more people in the last } \\
7 \text { days }\end{array}$ \\
\hline $\begin{array}{l}\text { 6. Unexpected large numbers of children absent from same } \\
\text { school due to the same illness } \\
\text { 7. An unexplained die-off of poultry or other domestic animals } \\
\text { 8. Illness with novel or rare symptoms in the community } \\
\text { 9. Unusual unexpected increases in sales at pharmacies of cough } \\
\text { medicines or antipyretics or diarrhea drugs within } 1 \text { week in a } \\
\text { same community }\end{array}$ & $\begin{array}{l}\text { 5. Unexpected large numbers of: } \\
\text { - Children absent from school due to the same illness in } \\
\text { the same 7-day period } \\
\text { - Sales at pharmacies of many people buying medicines } \\
\text { for the same kind of illness } \\
\text { - People sick with the similar type of symptoms at the } \\
\text { same time } \\
\text { - Deaths of poultry or other domestic animals }\end{array}$ \\
\hline
\end{tabular}

${ }^{a}$ This category was reorganized and split into 2 categories for Phase 2 .

${ }^{\mathrm{b}} \mathrm{A}$ signal to detect potential cases of measles was added.

'Increased specificity of the signals to decrease spurious reports.

${ }^{\mathrm{d}}$ Signal case definition was simplified.

'The signal was more clearly elucidated.

The event-to-signal ratio was found to be significantly higher in the Phase 2 provinces, after the revision of signals, when compared to the first 5 months of community eventbased surveillance implementation in Phase 1 provinces (mean 0.12 vs 0.06 , respectively; $p=0.03$ ).

The median number of signals reported per commune per month for all provinces was 0.3 and ranged from 0.03 to 2.8 signals.

Phase 1 provinces included 31 rural and 12 urban districts. The population sizes of the 43 participating districts varied considerably, ranging from a total population of 4,985 in Co To district (Quang Ninh province) to 345,200 in Cho Moi district (An Giang province). Population densities ranged from 32.7 per $\mathrm{km}^{2}$ in Ba Che (Quang Ninh province) to 5,286 per $\mathrm{km}^{2}$ in Nam Dinh city (Nam Dinh province). Village health worker density ranged from 0.39 per 1,000 population in Long Xuyen (An Giang province) to 4.4 per 1,000 population in Hai Ha (Quang Ninh province) (see Supplemental Material, https://www.liebertpub.com/ suppl/doi/10.1089/hs.2018.0066). 
Table 2. List of Events Detected from Phase 1 and Phase 2 Provinces from September 2016 to December 2017

\begin{tabular}{lc}
\hline Type of Events Reported & Number \\
\hline Hand, foot, and mouth disease & 60 \\
Suspect dengue & 54 \\
Chickenpox & 54 \\
Suspect mumps & 21 \\
Acute respiratory infection & 15 \\
Foodborne disease & 14 \\
Avian influenza in poultry & 12 \\
Suspect rabies exposure in humans & 7 \\
Conjunctivitis & 5 \\
Unexpected die-off among poultry & 3 \\
Toxin-related illness/death & 2 \\
Complication after vaccination & 2 \\
Suspect malaria & 1 \\
Neonatal tetanus & 1 \\
Birth defect, unusually small head & 1 \\
Human Streptococcus suis case & 1 \\
\hline Total & 253 \\
\hline
\end{tabular}

A total of $1,633(22 \%)$ of the 7,160 village health workers, 428/475 commune health stations (90\%), 39/43 district health centers $(91 \%)$, and all 4 Phase 1 provincial preventive medicine centers completed the online survey by June 30, 2017, from which other characteristics were derived. Survey participation varied markedly, from $52 \%$ of the village health worker respondents in Nam Dinh province to $8 \%$ in Ba RiaVung Tau (BRVT) province. Responses from commune health station and district health center respondents paralleled that of village health worker respondents in each province. Based on the survey results, $67 \%$ of village health workers were over the age of 40 years (range: $26 \%-100 \%$ by district), and $72 \%$ (range: $0 \%-100 \%$ by district) were female. More than half (61\%, range: $0 \%-100 \%$ by district) of village health workers had education beyond primary school (grade 6).

The 2 groups of key informants most commonly identified by commune health station focal points were community members $(76 \%, 40 \%-100 \%$ by district $)$ and school teachers (59\%, 0\%-100\% by district) (Table 3). Five characteristics were associated with differences in district-level

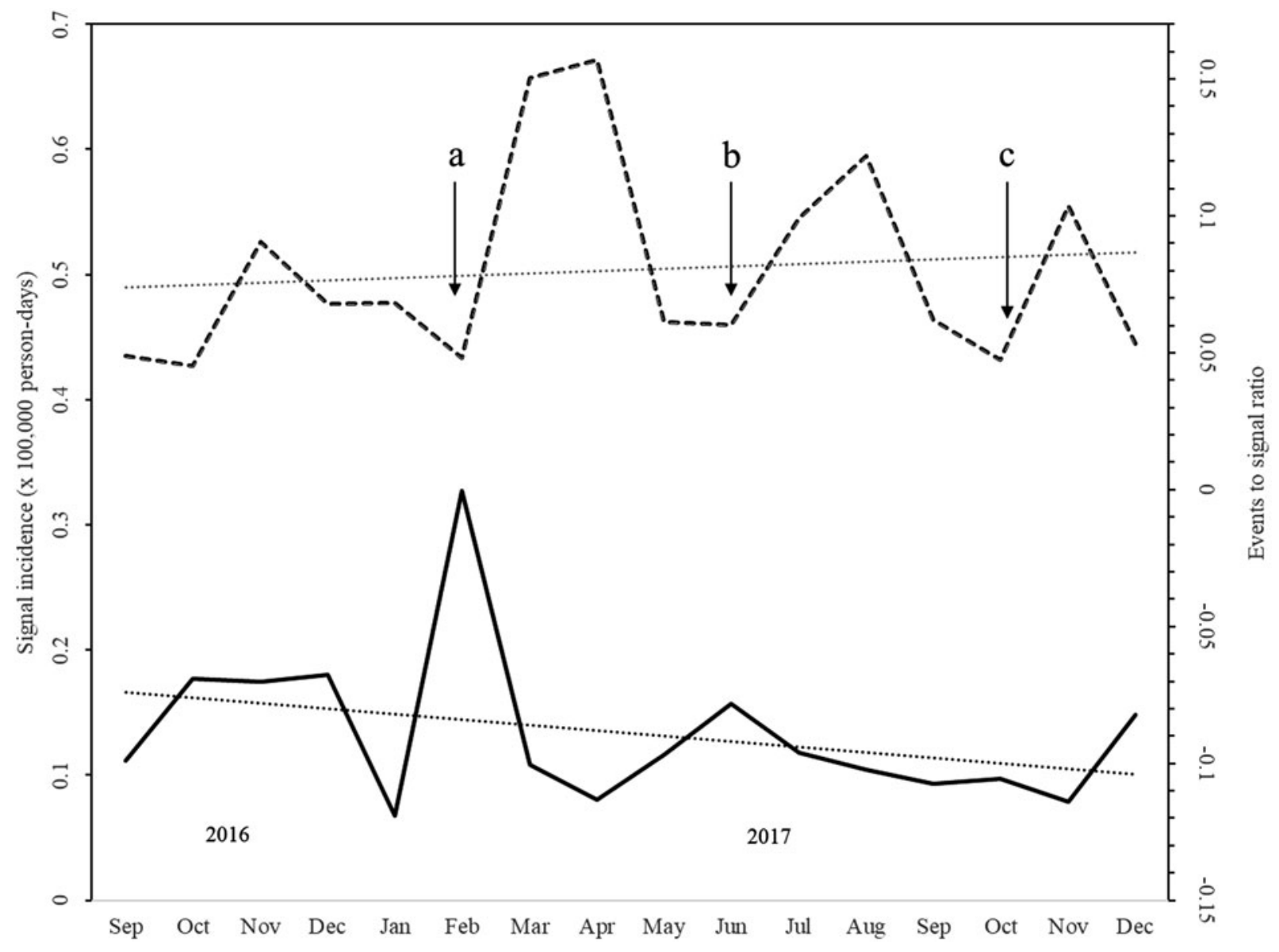

Figure 2. Signal incidence (solid line, left axis) and event-to-signal ratio (dashed line, right axis) over time. Linear trends are represented by dotted lines and over time show a slight decreasing signal incidence and a slight increasing event-to-signal ratio. Arrows $a, b$, and $c$ represent the interactions between ministry of health leadership and event-based surveillance implementers, namely the midterm progress check, evaluation, and signal revision, respectively. These data were collected from Phase 1 from September 2016 to December 2017. 
CLARA ET AL

Table 3. Potential Factors Associated with Signal Incidence from Phase 1 Provinces from September 2016 to June 2017

\begin{tabular}{|c|c|c|}
\hline Potential Factors Associated with Signal Incidence & Median (range) & $\mathrm{p}$ Value \\
\hline $\mathrm{VHW}^{\mathrm{a}}$ density (\# VHW/1,000 population) & $1.2(0.4-4.4)$ & $<0.01$ \\
\hline VHW, \% respondents with age $>40$ years $^{\mathrm{b}}$ & $67(26-100)$ & 0.88 \\
\hline VHW, \% respondents with age $>49$ years $^{\mathrm{b}}$ & $33(0-100)$ & 0.33 \\
\hline VHW, \% of respondents who are female ${ }^{b}$ & $72(0-100)$ & 0.36 \\
\hline VHW, \% of respondents with secondary school education ${ }^{b}$ & $61(0-100)$ & 0.15 \\
\hline Population & $134,401(4,985-345,200)$ & $<0.01$ \\
\hline Population density (population $/ \mathrm{km}^{2}$ ) & $523.4(32.7-5,286.7)$ & 0.047 \\
\hline $\begin{array}{l}\% \text { of communities in each district with community } \\
\text { members as active informants }\end{array}$ & $76(40-100)$ & 0.02 \\
\hline $\begin{array}{l}\% \text { of communities in each district with teachers as } \\
\text { active informants }\end{array}$ & $59.2(0-100)$ & $<0.01$ \\
\hline
\end{tabular}

${ }^{\mathrm{a}} \mathrm{VHW}=$ village health worker.

${ }^{\mathrm{b}}$ Factors that are VHW attributes are reported as the percentage of survey respondents.

signal incidence calculated in the univariate analysis. Three had a positive association: village health worker density $(r=0.563$, $p<0.010$ ), and the percentage of communities in each district with community members and teachers as active informants $(r=0.375, p=0.020$ and $r=0.506, p<0.010$ for community members and teachers, respectively). However, when these associations were examined for rural and urban districts separately, they remained significant only for rural districts (Table 4). Two factors had a negative association with signal incidence: total population $(r=-0.472, p<0.010)$ and population density $(r=-0.305, p=0.047)$. Notably, rural districts and urban districts did not differ significantly in their signal incidence ( 0.30 vs 0.22 per 100,000 person days, respectively) (Table 3).

Total population, population density, village health worker density, and the percentage of communities in the districts with community members and teachers as ac- tive informants were incorporated into a multivariate linear regression model. Of these, only 2 variables, village health worker density $(\beta=0.199, p=0.015)$ and the percentage of communities in the districts with teachers as active informants $(\beta=0.008, p=0.024)$, remained significant; together, they explained a significant proportion of incidence rate variability $\left(\mathrm{R}^{2}=0.46, p<0.010\right)$ (Table 5). We tested for signal incidence modification by incorporating a type of district interaction term. No significant interaction was found between village health worker density and the percentage of communities in the districts with teachers as active informants with the district type (rural vs urban) in their effect on signal incidence rate.

The survey asked questions to better understand implementers' opinions regarding the program, training, and support. Ninety-one percent of village health workers and

Table 4. Bivariate Analysis of Factors and Signal Incidence Showing a Significant Association with Signal Incidence in Rural Districts ${ }^{\mathrm{a}}$

\begin{tabular}{|c|c|c|c|c|c|c|}
\hline \multirow[b]{3}{*}{ Factors } & \multicolumn{6}{|c|}{ Type of Districts } \\
\hline & \multicolumn{2}{|c|}{ Urban } & \multicolumn{2}{|c|}{ Rural } & \multicolumn{2}{|c|}{ Overall } \\
\hline & $\mathrm{r}$ & $\mathrm{p}$ Value & r & p Value & $\mathrm{r}$ & $\mathrm{p}$ Value \\
\hline Population & -0.33 & 0.30 & -0.50 & $<0.01$ & -0.47 & $<0.01$ \\
\hline Population density $\left(\mathrm{km}^{2}\right)$ & -0.40 & 0.20 & -0.44 & 0.01 & -0.31 & 0.05 \\
\hline VHW' density (\# VHW/1,000 population) & 0.20 & 0.54 & 0.60 & $<0.01$ & 0.56 & $<0.01$ \\
\hline $\begin{array}{l}\% \text { of communities in each district with community } \\
\text { members as active informants }\end{array}$ & 0.24 & 0.47 & 0.41 & 0.03 & 0.38 & 0.02 \\
\hline $\begin{array}{l}\% \text { of communities in each district with teachers } \\
\text { as active informants }\end{array}$ & 0.41 & 0.21 & 0.53 & 0.01 & 0.51 & $<0.01$ \\
\hline
\end{tabular}

${ }^{\mathrm{a}}$ Data are from Phase 1 provinces from September 2016 to June 2017.

${ }^{\mathrm{b}} \mathrm{VHW}=$ village health worker . 
Table 5. Results of Linear Regression Analysis Showing Variables Associated with Signal Incidence and Interactions ${ }^{\mathrm{a}}$

\begin{tabular}{|c|c|c|c|c|c|c|c|c|}
\hline \multirow{3}{*}{$\begin{array}{l}\text { Variables } \\
\text { Total population }\end{array}$} & \multicolumn{4}{|c|}{ Model Without Interactions } & \multicolumn{4}{|c|}{ Model with Interaction Terms } \\
\hline & \multirow{2}{*}{$\frac{\beta}{0.00}$} & \multirow{2}{*}{$\begin{array}{l}p \text { Value } \\
0.44\end{array}$} & \multicolumn{2}{|c|}{$95 \%$ CI for B } & \multirow[t]{2}{*}{$\beta$} & \multirow[t]{2}{*}{$p$ Value } & \multicolumn{2}{|c|}{$95 \%$ CI for B } \\
\hline & & & 0.00 & 0.00 & & & & \\
\hline Population density & 0.00 & 0.94 & 0.00 & 0.00 & - & - & - & - \\
\hline VHW $^{\mathrm{b}}$ density & 0.119 & $0.015^{\mathrm{c}}$ & 0.04 & 0.36 & 0.263 & $<0.01^{\mathrm{c}}$ & 0.137 & 0.39 \\
\hline $\begin{array}{l}\% \text { of communities in each district with com- } \\
\text { munity members as active informants }\end{array}$ & 0.006 & 0.142 & -0.002 & 0.014 & - & - & - & - \\
\hline $\begin{array}{l}\% \text { of communities in each district with teachers } \\
\text { as active informants }\end{array}$ & 0.008 & $0.024^{\mathrm{c}}$ & 0.001 & 0.014 & 0.010 & $<0.01^{\mathrm{c}}$ & 0.004 & 0.016 \\
\hline Constant & -0.751 & 0.059 & -1.53 & 0.03 & -0.707 & $<0.01$ & -1.1 & -0.324 \\
\hline \multicolumn{9}{|l|}{ Interaction Terms } \\
\hline Type of district & - & - & - & - & 0.390 & 0.430 & -0.579 & 1.36 \\
\hline Interaction: VHW density AND type of district & - & - & - & - & -0.125 & 0.558 & -0.542 & 0.292 \\
\hline $\begin{array}{l}\text { Interaction: } \% \text { of communities in each district } \\
\text { with teachers as active informants AND type } \\
\text { of district }\end{array}$ & - & - & - & - & -0.003 & 0.668 & -0.017 & 0.011 \\
\hline
\end{tabular}

${ }^{\mathrm{a}}$ Data are from Phase 1 provinces from September 2016 to June 2017.

${ }^{\mathrm{b}} \mathrm{VHW}=$ village health worker.

${ }^{\mathrm{c}}$ Statistical significance at the $95 \%$ confidence level $(p<0.05)$

commune health station focal points and $87 \%$ of district focal points for community event-based surveillance reported that, as a result of training, they understood how to recognize, triage, and verify community event-based surveillance signals, and that they knew how to report community event-based surveillance data to the public health unit above them (Figure 3). A majority of respondents indicated that they received enough support from the levels above them: $94 \%$ from the commune health station, $92 \%$ from the district level, and $84 \%$ from the province level. Notably, a large majority of workers ( $89 \%$ of village health workers and commune health station focal points) and a similar number of district focal points $(90 \%)$ reported a willingness to continue conducting community event-based surveillance, stating that it was useful for detecting outbreaks. Most workers at the commune level felt that additional training and guidelines were needed and listed insufficient training as a barrier for successful community event-based surveillance $(77 \%$ of village health workers and commune health stations, and $59 \%$ for district health centers).

\section{Discussion}

Direct community involvement in the detection and reporting of potentially important public health events can overcome many limitations of routine indicator-based surveillance in detecting outbreaks while they are small and localized. ${ }^{13-17}$ In the past, most community-based surveillance programs have focused on reporting single diseases, such as a specific vaccine-preventable disease, or one targeted for elimination (eg, guinea worm). ${ }^{4,5,13,18}$ The current community event-based surveillance study took a broad approach, targeting the pathogens of highest concern to the ministry of health, and included signals that may detect emerging and reemerging threats as part of the development of an early warning and response system. Additionally, the community event-based surveillance project was launched on a large scale: This pilot involved $9 \%$ of the total population of the country, more than 8 million people.

During the evaluation of the pilot, we identified several factors that we believe were responsible for the success of the project. The number of village health workers per population was associated with a higher reporting of signals, and teachers were identified as a major source of those signals. The important role of teachers in community event-based surveillance was further reflected in the observation that a large portion of the detected events were vaccine-preventable diseases among children. In our study, differences in age, sex, and education level of village health workers did not appear to influence the level of signal reporting. However, reporting was highest when village health workers had been given instruction as part of a small group rather than being taught in a large classroom (data not shown). These factors seemed relevant primarily for rural settings.

Importantly, while the number of signals per unit of population trended slightly downward over the course of the 16 months of Phase 1 of the pilot, the quality of the reporting - that is, the proportion of signals that were judged to be events—-trended upwards and also appeared to 


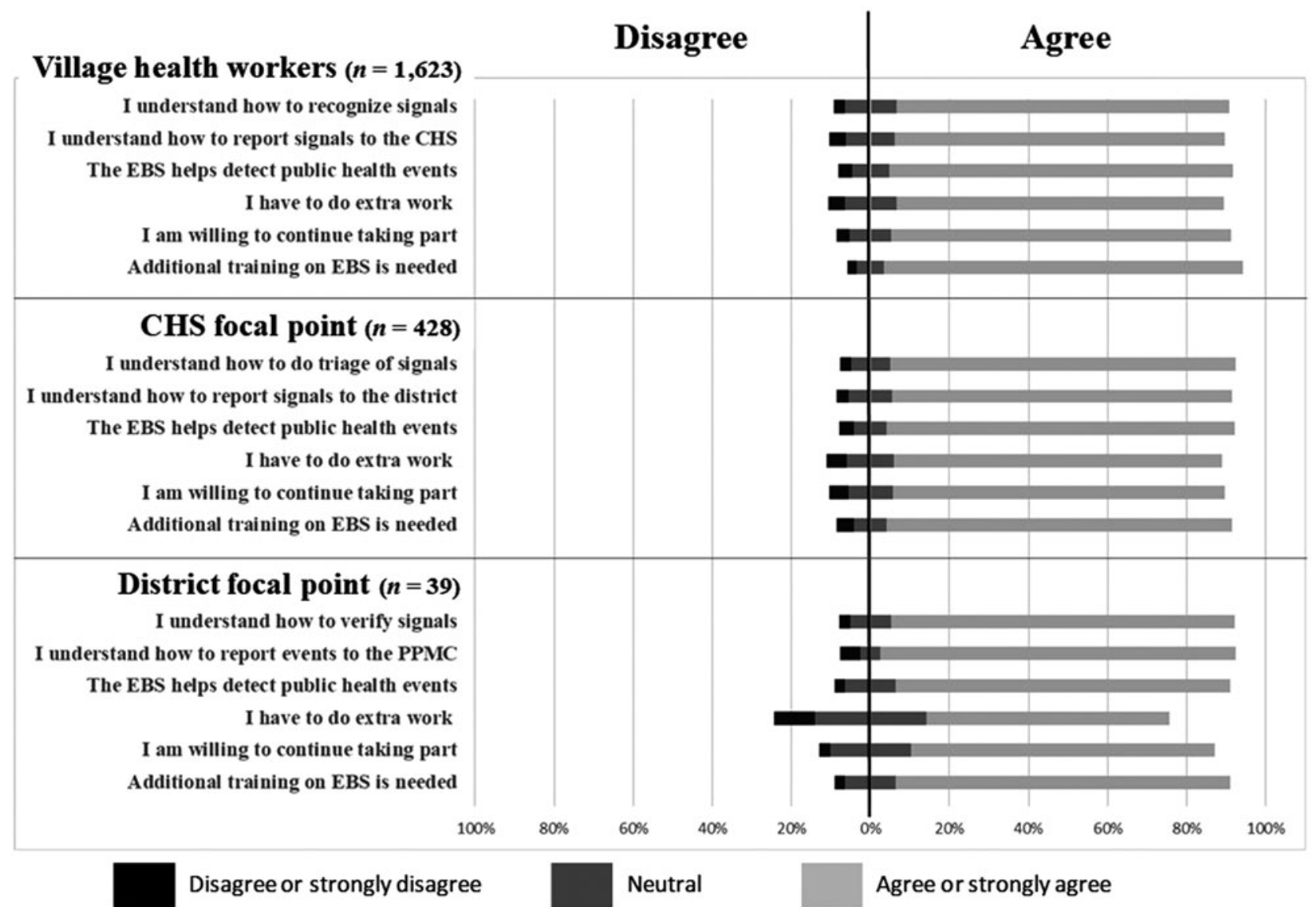

Figure 3. A selection of survey questions and responses related to attitudes and beliefs from the acceptability survey administered to village health workers (VHW), commune health station (CHS), and district focal points during Vietnam's community event-based surveillance pilot in 2017 .

improve sharply after specific times when the village health workers, commune health stations, district health centers, and provincial preventive medicine centers were engaged either in supportive monitoring or refresher training.

Our study found that commune health stations received less than 1 signal per month on average, and the busiest commune health station received fewer than 3 signals per month. Village health workers and other implementers did not report the work of community eventbased surveillance as an undue burden during face-to-face interviews. In fact, a small and continuous stream of signal reporting may serve as an important opportunity for public health authorities to encourage and sustain reporting behavior, as well as to maintain open channels of communication with the community.

Community event-based surveillance served as an effective One Health surveillance system, detecting signals associated with 3 of the 5 priority zoonoses in Vietnam: avian influenza, rabies, and infections with Streptococcus suis. ${ }^{19}$ In addition, the system was able to detect a toxin-mediated outbreak related to consumption of contaminated fish, a noninfectious event of notable public health significance for the community. Although none of the outbreaks that oc- curred during the course of the pilot were large nationwide events or posed a threat to the international community, the ongoing sustained reporting of smaller events gives us confidence that had such a large event occurred, it would have been detected and reported rapidly. We were not able to directly compare the impact of the program to non-pilot provinces, because other provinces in the country had no records of outbreak reporting. Thus, for the first time, the ministry of health has available to it important public health information on outbreaks of vaccine-preventable disease, foodborne disease, and zoonoses in the community that can be used to shape public health policy.

More than half the events reported during Phase 1 were dengue and hand, foot, and mouth disease, both of which are endemic seasonal diseases in Vietnam. Because they occur annually and over a broad area rather than in discrete outbreaks, these specific diseases are probably better suited for monitoring in a routine reporting system, such as one in a healthcare facility. Signals for these 2 diseases were removed from the signal list in Phase 2 of the pilot. In addition to this, the signals were revised to improve the clarity for lay workers, rearranged and regrouped for simplicity, and the specificity of certain signals was increased to 
decrease spurious reports. These modifications to the signal definitions, along with ongoing supportive supervision, resulted in overall improvements in the quality of reporting as reflected in the event-to-signal ratio.

The study had a number of limitations. First, although the online surveys were sent to all of the workforce in the 4 pilot provinces, only a relatively small proportion of village health worker respondents completed it, which limited the representativeness of some of the findings and may have skewed some of the analyses. Without knowing the demographic profiles of nonrespondents, there may have been undetected bias in survey respondents. In addition, there may be specific factors such as community composition and cultural issues that play a role in the effectiveness of village health workers that were not captured by our study. Finally, it was not possible to include all district health centers, commune health stations, and communes participating in the pilot in the site visits and some qualitative data collection, and the degree to which the included districts represent the whole is uncertain.

The community event-based surveillance pilot has demonstrated several issues that need further study: (1) the need to develop better tools to measure the impact of community event-based surveillance including sensitivity and positive predictive value when the total number of events that has occurred is unknowable; (2) development of effective training strategies to efficiently train large numbers of widely dispersed health workers (and the potential utility of electronic training platforms); (3) signal definitions that give the best balance of sensitivity and specificity and effectively signal for an unknown, novel pathogen; (4) the utility of electronic data collection and signal reporting methods; and (5) methods to motivate village and community health workers in a sustainable way.

We found that the use of sensitized key informants from within the community who are likely to have knowledge of events occurring around them is an effective way to quickly establish "eyes and ears" on the ground and also likely helped to limit the amount of signal noise that might occur if all members of a community were invited to report. It may be that over a longer period of time, districts with a lower number of village health workers may catch up with those that have higher numbers through the accumulation of informant networks over time.

The finding that the number of village health workers and other reporters was most important in rural districts deserves further study. It may reflect less community cohesion in urban areas, resulting in less connectedness and fewer social networks. Village health workers from rural areas commonly and spontaneously reported that they were well respected and recognized by their communities, while interviewers were less likely to hear this sentiment expressed among village health workers working in urban areas.

In summary, this pilot project has demonstrated that community event-based surveillance can be an important complement to other types of surveillance and may be useful for the early detection of outbreaks, potentially before the pathogen is even recognized. As such, it should be considered a key component of global health security. ${ }^{20}$

This pilot implementation experience helped the ministry of health to meet its requirements under the IHR and strengthen capacities within the GHSA framework. More importantly, it created a framework that improves the system's ability to detect and respond to outbreaks at their source as they emerge. As a result of the success of the pilot, the vice minister of health of Vietnam issued a mandate in March 2018, Decision No. 2018/QD-BYT, that directed all provinces to integrate event-based surveillance into the national surveillance strategy, ensuring sustainability of the community event-based surveillance program. ${ }^{21} \mathrm{We}$ believe that the lessons learned from the community event-based surveillance implementation in Vietnam can guide the development of similar programs in other countries.

\section{ACKNOWLEDGMents}

The pilot project was funded by Global Health Security Agenda funds provided through a cooperative agreement between the US Centers for Disease Control and Prevention and the Vietnam Ministry of Health's General Department of Preventive Medicine.

\section{REFERENCES}

1. Dagina R, Murhekar M, Rosewell A, Pavlin BI. Event-based surveillance in Papua New Guinea: strengthening an International Health Regulations (2005) core capacity. Western Pac Surveill Response J 2013;4(3):19-25.

2. Toyama Y, Ota M, Beyene BB. Event-based surveillance in north-western Ethiopia: experience and lessons learnt in the field. Western Pac Surveill Response J 2015;6(3):22-27.

3. Santa-Olalla P, Gayer M, Magloire R, et al. Implementation of an alert and response system in Haiti during the early stage of the response to the cholera epidemic. Am J Trop Med Hyg 2013;89(4):688-697.

4. Curry D, Bisrat F, Coates E, Altman P. Reaching beyond the health post: community-based surveillance for polio eradication. Dev Pract 2013;23:69-78.

5. Crowe $S$, Hertz D, Maenner M, et al. A plan for community event-based surveillance to reduce Ebola transmissionSierra Leone, 2014-2015. MMRW Morb Mortal Wkly Rep 2015;64(3):70-73.

6. Ratnayake R, Crowe SJ, Jasperse J, et al. Assessment of community event-based surveillance for Ebola virus disease, Sierra Leone, 2015. Emerg Infect Dis 2016;22(8):1431-1437.

7. Ministry of Health of Liberia. Community Event-Based Surveillance Manual for Integrated Disease Surveillance and Response in Liberia. Monrovia, Liberia: Ministry of Health of Liberia; 2016. http://MoH.gov.lr/wp-content/uploads/2016/ 12/CEBS-Guidelines-FINAL-MAY.pdf. Accessed September 9, 2018. 
8. World Health Organization Regional Office for the Western Pacific. A Guide to Establishing Event-Based Surveillance. Manila, The Philippines: World Health Organization Regional Office for the Western Pacific; 2008. http://www. wpro.who.int/emerging_diseases/documents/docs/eventbased surv.pdf. Accessed September 9, 2018.

9. World Health Organization. Early Detection, Assessment and Response to Acute Public Health Events: Implementation of Early Warning and Response with a Focus on Event-Based Surveillance. Interim Version. Geneva, Switzerland: World Health Organization; 2014. http://apps.who.int/iris/bitstream/handle/10665/ 112667/WHO_HSE_GCR_LYO_2014.4_eng.pdf;sequence= 1. Accessed September 9, 2018.

10. Clara A, Do TT, Dao ATP, et al. Event-based surveillance at community and healthcare facilities, Vietnam, 2016-2017. Emerg Infect Dis 2018;24(9):1649-1658.

11. Global Health Security Agenda. Updated May 20, 2018. https://www.ghsagenda.org/. Accessed September 9, 2018.

12. General Statistics Office of Vietnam. The 2009 Vietnam population and housing census: completed results. Ha Noi, Vietnam: General Statistics Office of Vietnam; 2010. http://www. gso.gov.vn/default_en. aspx?tabid=476\&idmid=\&ItemID= 10802. Accessed September 9, 2018.

13. Ndiaye SM, Quick L, Sanda O, Niandou S. The value of community participation in disease surveillance: a case study from Niger. Health Promot Int 2003;18(2):89-98.

14. Freifeld CC, Chunara R, Mekaru SR, et al. Participatory epidemiology: use of mobile phones for community-based health reporting. PLoS Med 2010;7(12):e1000376.

15. Morse SS. Public health surveillance and infectious disease detection. Biosecur Bioterror 2012;10(1):6-16.
16. Jost CC, Mariner JC, Roeder PL, Sawitri E, MacgregorSkinner GJ. Participatory epidemiology in disease surveillance and research. Rev Sci Tech 2007;26(3):537-549.

17. Nikolay B, Salje H, Sturm-Ramirez K, et al. Evaluating hospital-based surveillance for outbreak detection in Bangladesh: analysis of healthcare utilization data. PLoS Med 2017;14(1):e1002218.

18. Cairncross S, Braide EI, Bugri SZ. Community participation in the eradication of guinea worm disease. Acta Trop 1996; 61(2):121-136.

19. Do TT, Siembieda J, Nguyen TH, et al. Prioritization of zoonotic diseases of public health significance in Vietnam. $J$ Infect Dev Ctries 2015;9(12):1315-1322.

20. Katz R, Sorrell EM, Kornblet SA, Fischer JE. Global Health Security Agenda and the International Health Regulations: moving forward. Biosecur Bioterror 2014;12(5):231-238.

21. General Department of Preventive Medicine, Ministry of Health, Socialist Republic of Viet Nam. Decision: instructing that all provinces have to integrate event-based surveillance (EBS) into the national surveillance strategy. No. 2018/QD-DP. Hanoi (Vietnam): Vietnam Ministry of Health; 2018.

Address correspondence to: S. Arunmozhi Balajee, PhD Associate Director, Global Health Systems Centers for Disease Control and Prevention 1600 Clifton Rd. Atlanta, GA 30333

Email: fir3@cdc.gov 